\title{
International Day of Light (IDL): a new forum for interdisciplinary learning concepts in optics and photonics
}

Dan Curticapean, Oliver Vauderwange, Benjamin Heitz

Dan Curticapean, Oliver Vauderwange, Benjamin Heitz, "International Day of Light (IDL): a new forum for interdisciplinary learning concepts in optics and photonics," Proc. SPIE 11143, Fifteenth Conference on Education and Training in Optics and Photonics: ETOP 2019, 1114334 (2 July 2019); doi: $10.1117 / 12.2523411$ Photonics: ETOP 2019, 2019, Quebec City, Quebec, Canada 


\title{
International Day of Light IDL - A New Forum for Interdisciplinary Learning Concepts in Optics and Photonics
}

\author{
Dan Curticapean $^{\mathrm{a}}$, Oliver Vauderwange ${ }^{\mathrm{a}}$, Benjamin Heitz ${ }^{\mathrm{a}}$ \\ ${ }^{a}$ Offenburg University, Badstr. 24, 77652 Offenburg, Germany \\ Keywords: Education in Optics and Photonics, International Year of Light, IYL, \\ International Day of Light, IDL
}

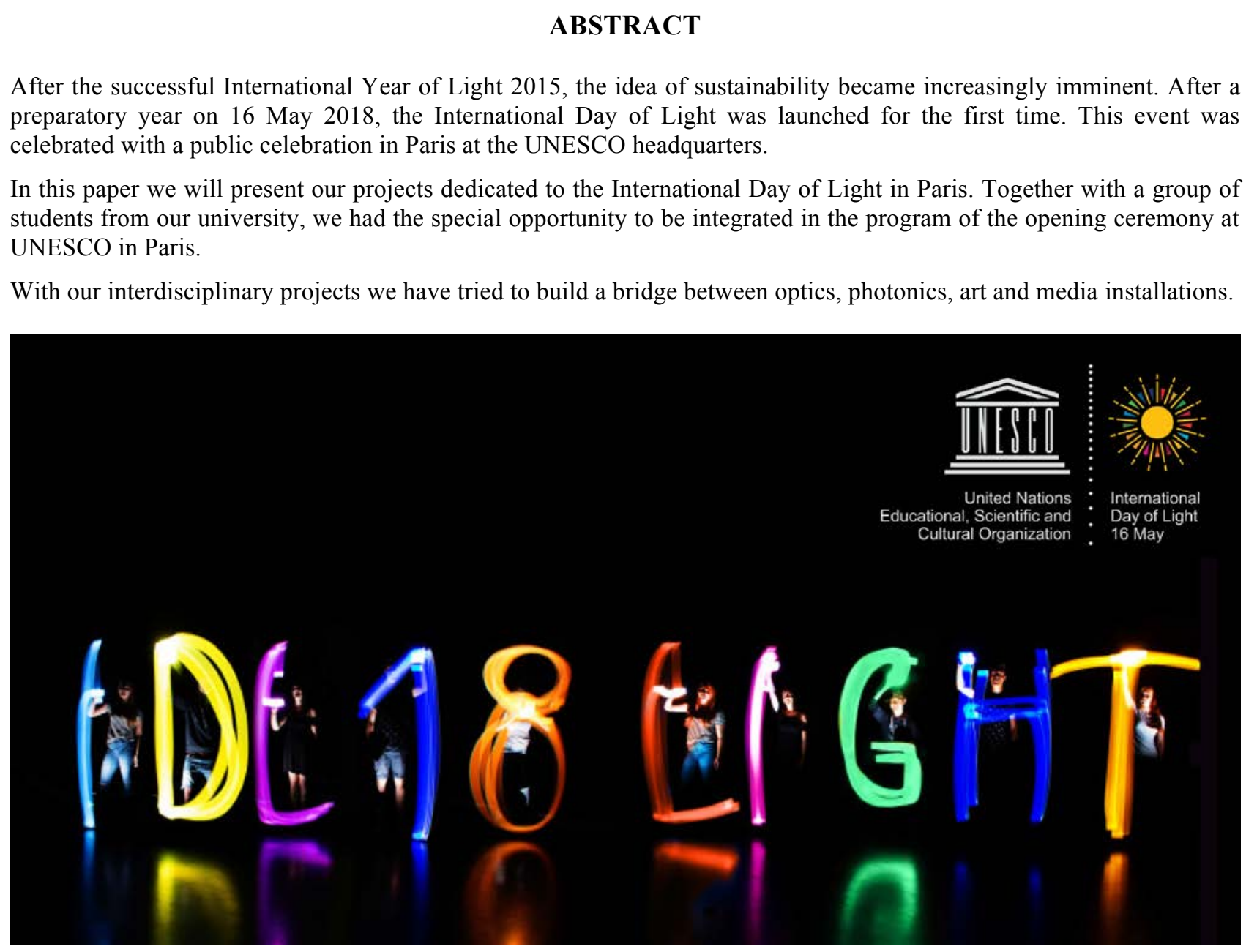

Fig. 1: International Day of Light 2018 Postcard (C) Authors

* dan.curticapean@hs-offenburg.de, phone 0049781205 372, offenburg-university.de/curticapean

Fifteenth Conference on Education and Training in Optics and Photonics: ETOP 2019, edited by Anne-Sophie Poulin-Girard, Joseph A. Shaw, Proc. of SPIE Vol. 11143, 1114334 - (c) 2019 SPIE, ICO, IEEE, OSA · CCC code: 0277-786X/19/\$18 · doi: 10.1117/12.2523411 


\section{INTRODUCTION}

The International Year of Light in 2015 [1] was celebrated in 147 countries worldwide. With more than 13,000 distinct events, reach an audience estimated at over 100 million, it turned out to be the most successful "International Year" celebrated by UNESCO [2]. The IYL 2015 website was accessed from 191 countries, and 24 commemorative postage stamps were created [3]. See the IYL 2015 Final Report for more information [2].

An important guarantor for its success was an excellent preparation process started several years in advance.

For us at Offenburg University it was a special pleasure to be involved in the preparations and implementation of the International Year of Light.

As a legacy of the IYL, we have used the opportunity and the gained momentum to continue in our activities. We have found it natural to carry on the idea of the IDL to further our existing projects and start new ones.

The resolution of the UNESCO Executive Council to introduce an

IDL on 16 May every year was endorsed by the UNESCO General Conference at its $39^{\text {th }}$ session on 7 November 2017 [3].

The International Day of Light is a global initiative that provides an annual focal point for the continued appreciation of light and the role it plays in science, culture and art, education, and sustainable development, and in fields as diverse as medicine, communications, and energy. The broad theme of light will allow many different sectors of society worldwide to participate in activities that demonstrates how science, technology, art and culture can help achieve the goals of UNESCO - education, equality, and peace [3].

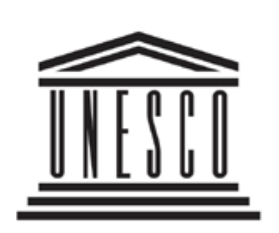

United Nations Educational, Scientific and Cultural Organization

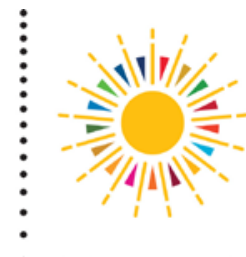

International

Day of Light 16 May The response to the International Day of Light 2019 (IDL) on May 16 is very large. According to the organizers, there will be over 200 events from 54 countries this year. Excitement Grows from year to year for the International Day of Light [3].

\section{MILESTONES 2015 IN LIGHT SCIENCE}

Several major anniversaries in 2015 have significantly influenced the attractiveness of IYL 2015 [2]. Among them are:

1015: Alhazen, Arabian mathematician, physicist and optician - inventor of the magnifying lens (loupe) -, completes his seven-volume treatise, "Treasure of Optics"

1615: French-Huguenot engineer Salomon de Caus invents the prototype of a solar-driven engine

1815: Augustin-Jean Fresnel introduces the theory of light as a wave

1865: James Clerk Maxwell rigorously describes the electromagnetic theory of light

1905: Albert Einstein published the explanation of the photoelectric effect, which earned him the Nobel Prize

1915: David Hilbert and Albert Einstein develop the theory of relativity, showing how light is at the center of the very structure of space and time

1965: Arno Allan Penzias and Robert W. Wilson discover the cosmic microwave background, an electromagnetic echo of the very creation of the universe

1965: Charles Kuen Kao and optical fibre technology

Furthermore, we have tried to reach and inspire young people, secondary-school and university students, by way of the exciting innovations and biographies of renowned scientists. 


\section{INAUGURATION CEREMONY OF THE INTERNATIONAL DAY OF LIGHT AT THE UNESCO IN PARIS}

The IDL2018 kicked off on 16.May 2018, with the inauguration ceremony at the UNESCO Headquarters in Paris, with more than 900 invited guests from all over the globe, representatives from science, politics and culture. The inauguration ceremony started with a message by Flavia Schlegel - UNESCO Assistant Director-General for Natural Sciences (Fig. 2) and the Official Inauguration Address by Audrey Azoulay, Director-General of UNESCO.
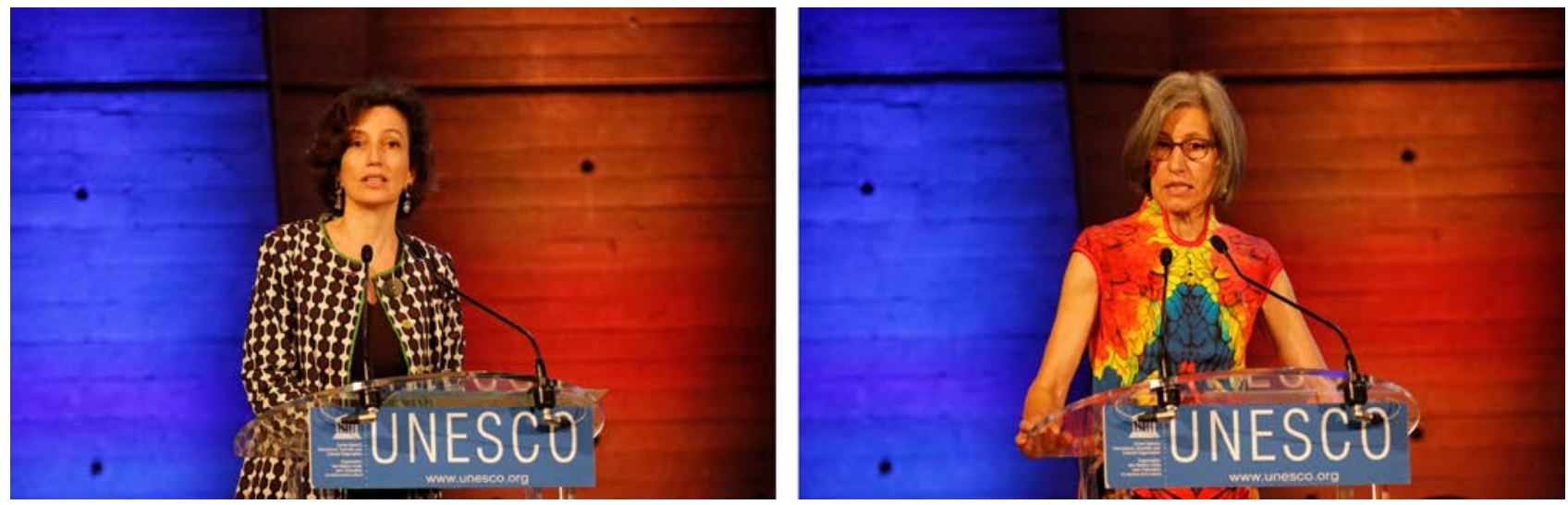

Fig. 2: Audrey Azoulay, Director-General of UNESCO and Flavia Schlegel - UNESCO Assistant Director-General

Talks by Nobel laureates - Kip Thorne and Claude Cohen-Tannoudji as well as by Khaled Toukan Director of SESAME synchrotron, markedly affected the high level of the academic part of the event.

A special aspect of the opening ceremony was the panel discussions all around the interdisciplinary fields of optics.

The inauguration ceremony was musically performed by Katerina Mina, soprano with music by Linda Lamon. Impressive optical effects were provided and after sunset, the UNESCO Headquarter facade was immersed in an expressive projection fig. 3.

During the inauguration ceremony, Offenburg University students presented the following interactive projects in the UNESCO Headquarter Foyer:

- „Twitterwall“ an interactive live projection in the UNESCO Foyer

- „A Maze: Ingenious Pipes” an interactive projection and photo shooting

- "The Power of Your Eyes" an interactive interdisciplinar art and photonics project

- HeNe Laser - Plasma Laser exhibition

- IDL 2018 - art postcard collection exhibition

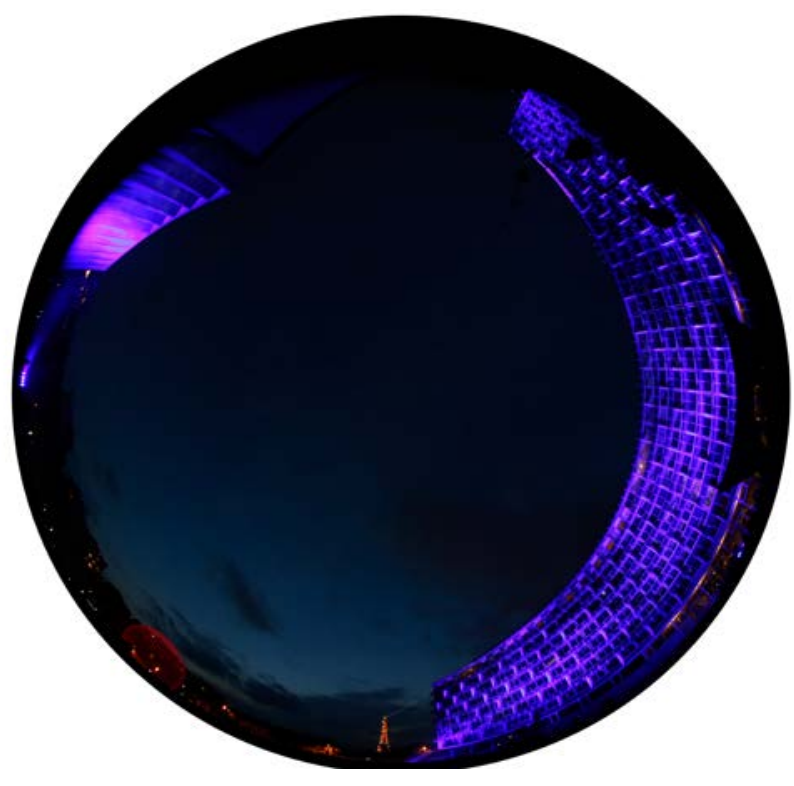

Fig.3: An impressive light projection on the UNESCO building

The projects are described briefly below. 


\section{4. „TWITTERWALL“ AN INTERACTIVE LIVE PROJECTION}

The interactive projection (Fig. 4) was shown in the foyer of the Paris UNESCO building during the inaugural ceremony of the International Day of Light at 18. May 2018, next to works by Picasso or Miró. Tweets placed for the inaugural ceremony by participants around the world - not just those present in Paris - were visualized and presented in an interactive projection. Using the hashtag \#id12018, Twitter messages could be sent to Paris and were then placed on a rotating globe showing the users' locations and messages. The interactive map highlighted the regions from which tweets originated in different colors. According to the number of tweets, the colors of the regions also changed, from yellow to dark red. In addition, the projections were streamed onto the IDL2018 website, so the participants were able to receive feedback and actively

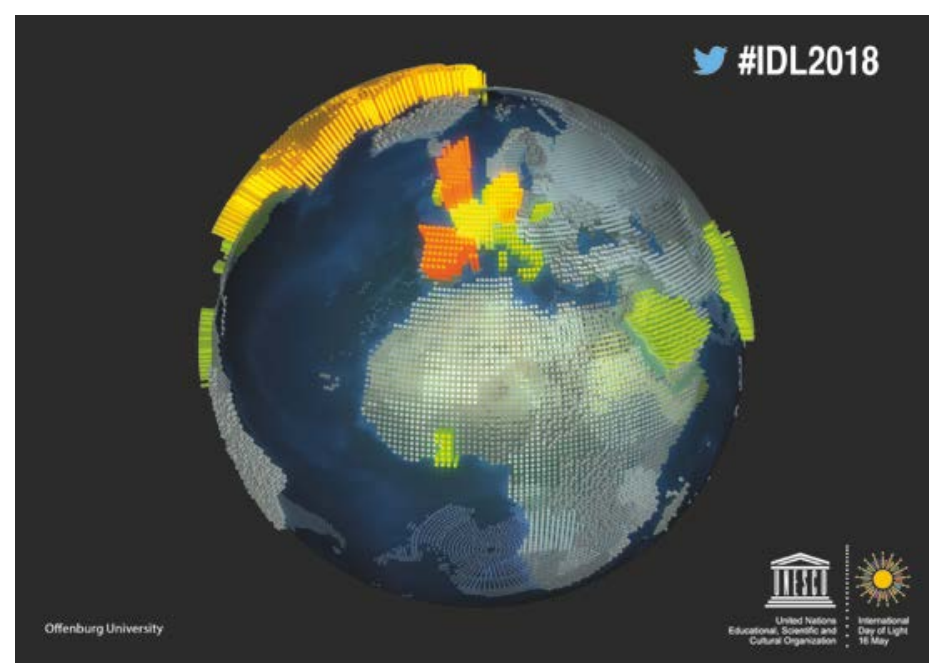

Fig. 4: Twitterwall for the IDL inaugural ceremony at UNESCO Paris participate in the opening even if they not be there [4].

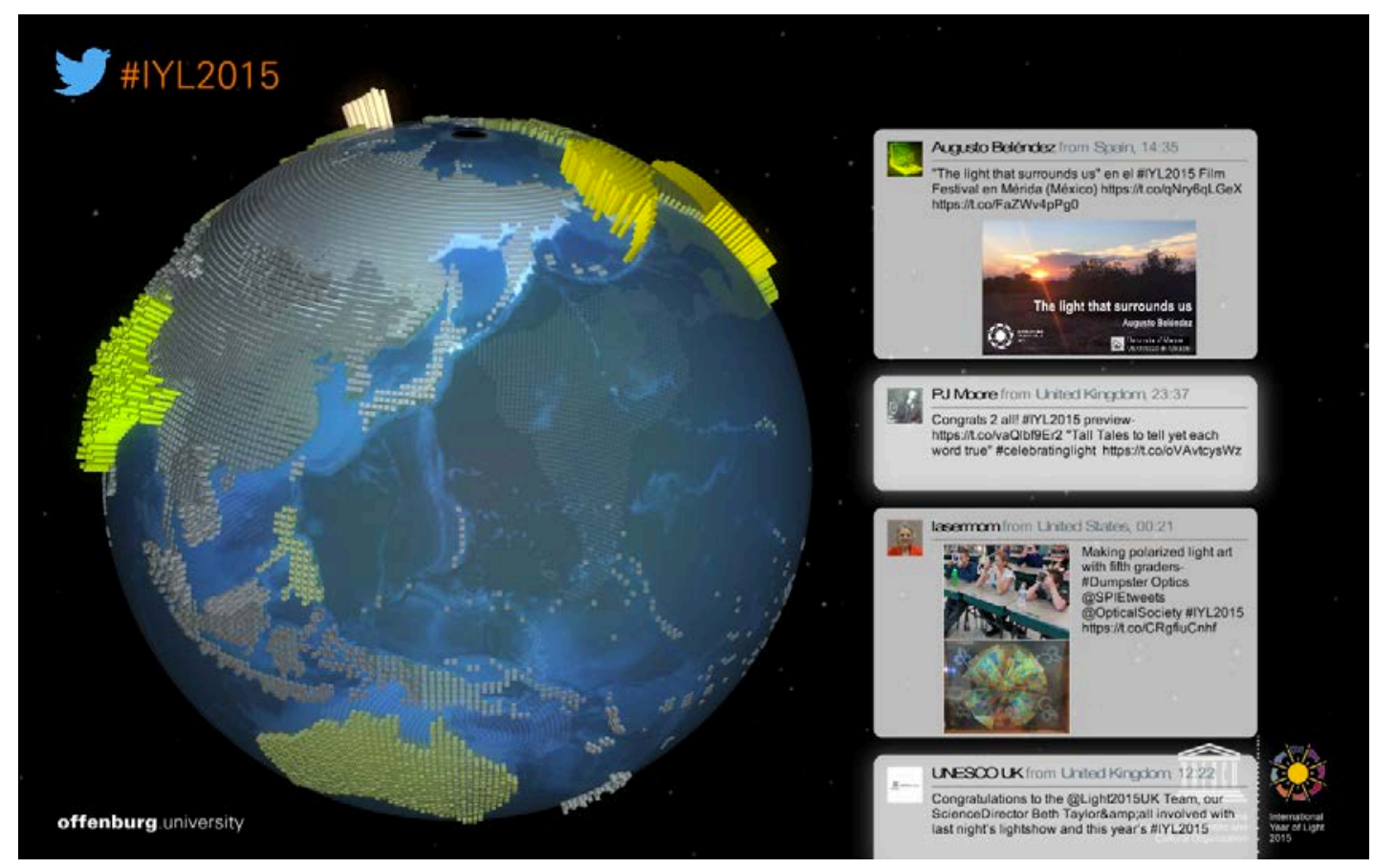

Fig. 5: Twitterwall screen shoot of a visualized tweet from the "lasermon" Judy Donnely during the IYL 


\section{5. "A MAZE: INGENIOUS PIPES" AN INTERACTIVE PROJECTION AND PHOTO SHOOTING}

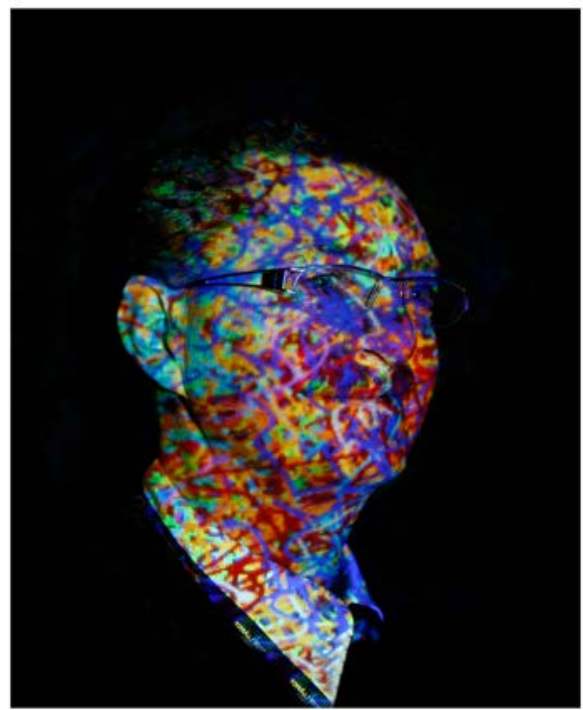

1) Hochschule Offenburg

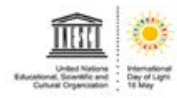

"A Maze: Ingenious Pipes" is an interactive project involving projection and photography. In a dark room, a pattern is projected onto the participants. The pattern is randomly generated by a computer and has an evolving shape similar to dendritic growth. The participants are given a self-timer and see themselves in a control monitor. Depending on the pattern the participant can trigger the timer and have the image printed out as a Polaroid photograph. Figure 6 shows Mister International Day of Light, John Dudley's result [4].

This project engaged a group of students, who had to bring in their combined knowledge of computer science, electrical engineering, design and photography to master the installation. Meanwhile we have added an extension such that the resulting image is sent to the participant's mobile phone and can be viewed in $3 \mathrm{D}$ using a cardboard.

Fig. 6: Result of "A Maze: Ingenious Pipes" in a "Polaroid" photograph (John Dudley)

\section{6. “THE POWER OF YOUR EYE" AN INTERACTIVE INTERDISCIPLINARY ART AND PHOTONICS PROJECT}

"The Power of Your Eye" is an interactive media installation based on the principle of eye tracking. The interaction is described on the postcard presented in Figure 7. The viewer looks at the screen and fixes their gaze on one of the circles on it. The fixated circle then begins to rotate; when it is fixated again, it comes to a standstill. To determine the position of the gaze, an eye-tracking bar is attached to the lower edge of the screen. In our media installation, a commercial eyetracking bar was used. It takes over the movement of the computer mouse, and is controlled accordingly by the participant's image [4].
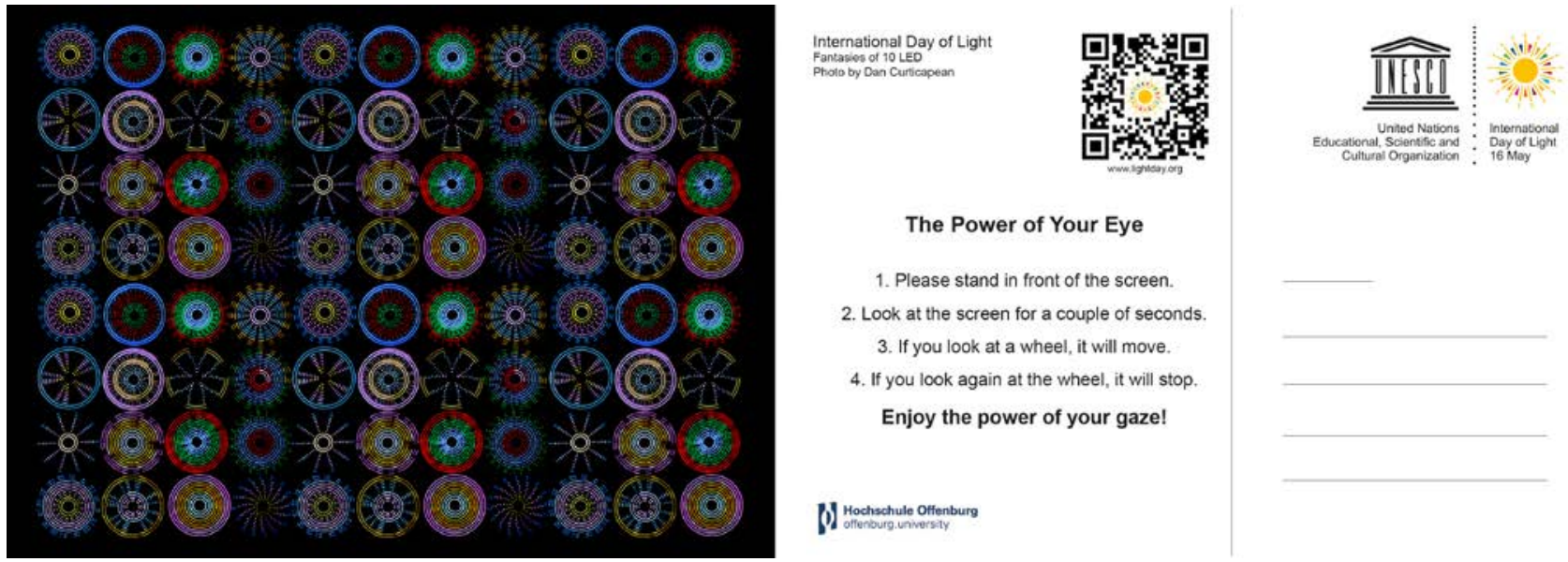

Fig. 7: The Power of Your Eye - Postcard with instructions on how to interact with the installation. 
The animation of the circles was programmed with Adobe Flash. The circles themselves are the result of different patterns created with ten LEDs on a rotating disk by long-term exposure. A special challenge was the calibration of the eye-tracking bar in order to match as large a number of participants as possible without calibrating for each individual.

\section{HELIUM NEON LASER - PLASMA LASER EXHIBITION}

To underline the special meaning of the day May 16, the day when the first laser operated (1960) [5], we set up a HeNe laser at the International Day of Light inauguration ceremony. It was not a ruby laser like Theodore Maiman's (Fig. 8) [6], but a HeNe plasma laser that was produced in the late 1960s. With this we wanted to draw the attention of the audience to the importance of the date. It is always a big highlight to operate an old HeNe plasma laser [7] (cf. Fig. 9)!

Some technical details: The helium-neon laser or simply $\mathrm{HeNe}$ laser, is a gas (plasma) laser and the gain medium consists of a mixture of $75 \%$ helium and $25 \%$ neon at a total pressure of about $1 \mathrm{~mm}$ of $\mathrm{Hg}$. The $\mathrm{HeNe}$ laser operates at a wavelength of $632.8 \mathrm{~nm}$, in the red part of the visible spectrum. The energy diagram of the $\mathrm{HeNe}$ laser is giving in Fig. 10 [7].

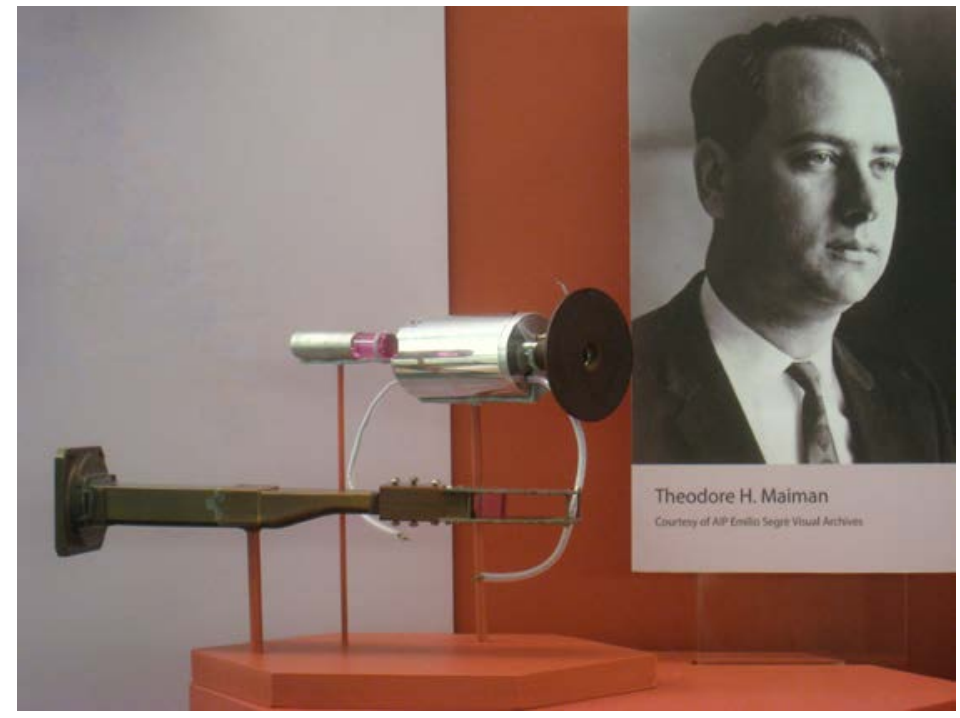

Fig. 8: Theodore Maiman and the first Laser Photo by Daderot Selfphotographed, Public Domain, https://commons.wikimedia.org/w/index.php?curid=12858444

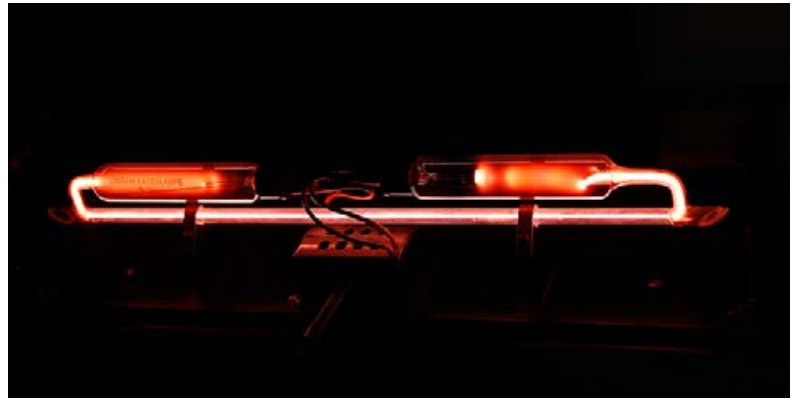

Fig. 9: HeNe Laser operating at the inaugural ceremony at UNESCO HQ in Paris Photo by Dan Curticapean

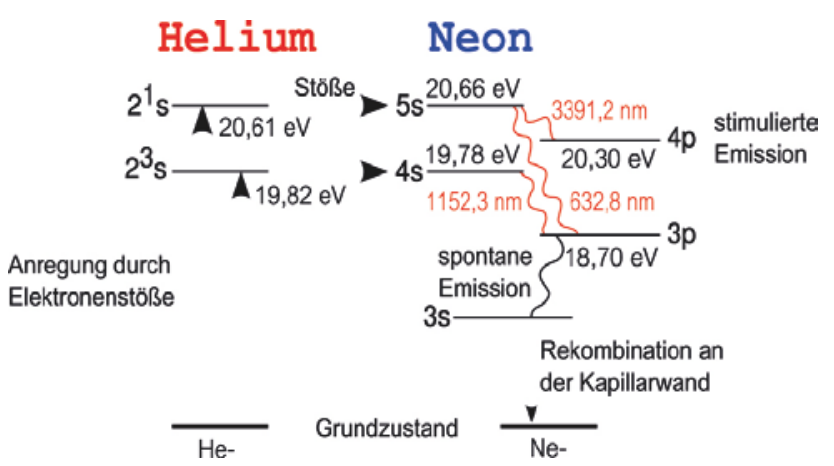

Fig. 10: Energy diagram of the helium neon laser (C) Bubinator, https://commons.wikimedia.org /w/index.php?curid=31457245 


\section{INTERNATIONAL DAY OF LIGHT ART POSTCARD COLLECTION}

To focus the attention on the International Day of Light, this author had designed a series of postcards in advance. The series was a synergy of physical experiments, photography and image processing. The results are presented in Figures 11-16 [4].
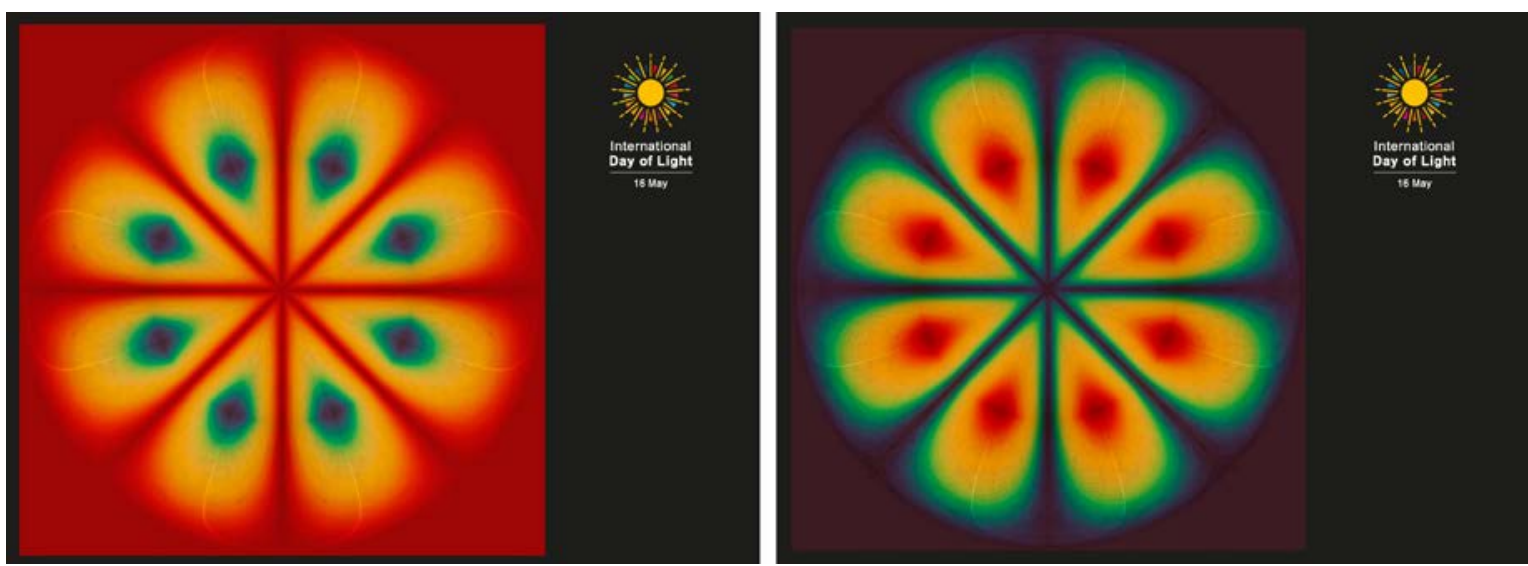

Fig. 11 - 12: Postcards IDL: Orbital Light Red - Orbital Light Blue; ㅇ Photos Dan Curticapean
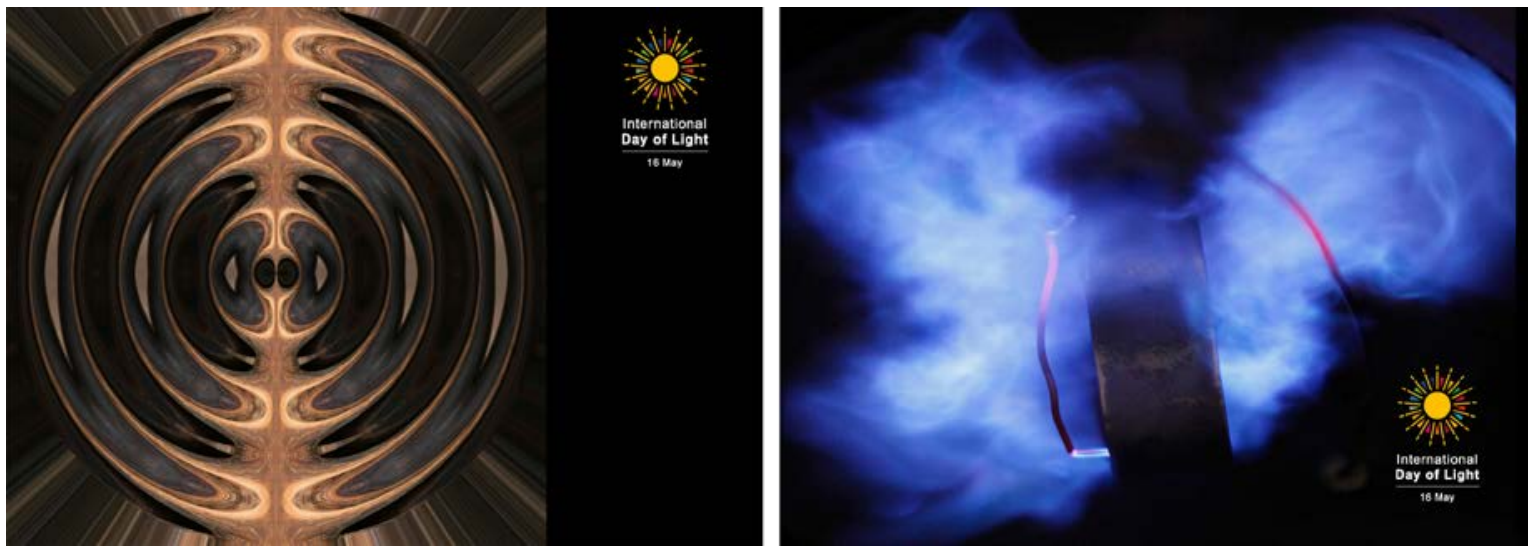

Fig. 13-14: Postcards IDL: Electromagnetic Waves - The Light Inside the Engine; $\subset$ Photos Dan Curticapean
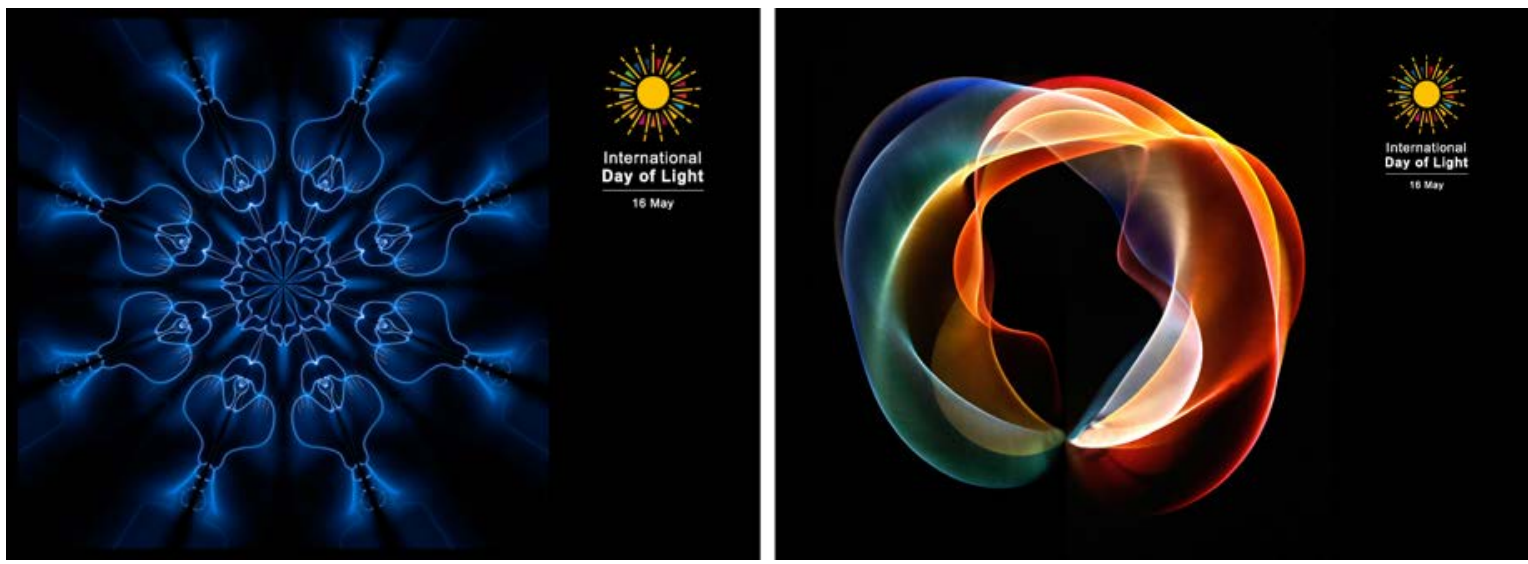

Fig. 15 - 16: Postcards IDL: Plasma Pseudosymmetry - Optical Möbius Strip II; C Photos Dan Curticapean 
The IDL Steering Committee selected one of the postcard motifs for long-term advertising (Fig. 1).

Some examples are shown in:

The IDL Steering Committee selected one of our postcard motifs for the long-term advertising (Fig. 1).

Some examples are shown in:

- $\quad$ Fig. 17: - The landing page of the IDL - Homepage - www.lightday.org ( 29.04.2019)

- Fig. 18: - John Dudley's talk (Chair IDL - Steering Committee) talk at the inauguration ceremony at UNESCO Paris 16.May 2018

- Fig. 19:- SPIE Social Media

- Fig. 20:- SPIE Poster collection at HQ UNESCO Paris

- $\quad$ Fig. 21: - SPIE - Public Relations - lenticular printed bookmark (give-away).

We would like to emphasize that many students were involved in the production of this photograph (Fig. 1) as part of a lecture for photographers.

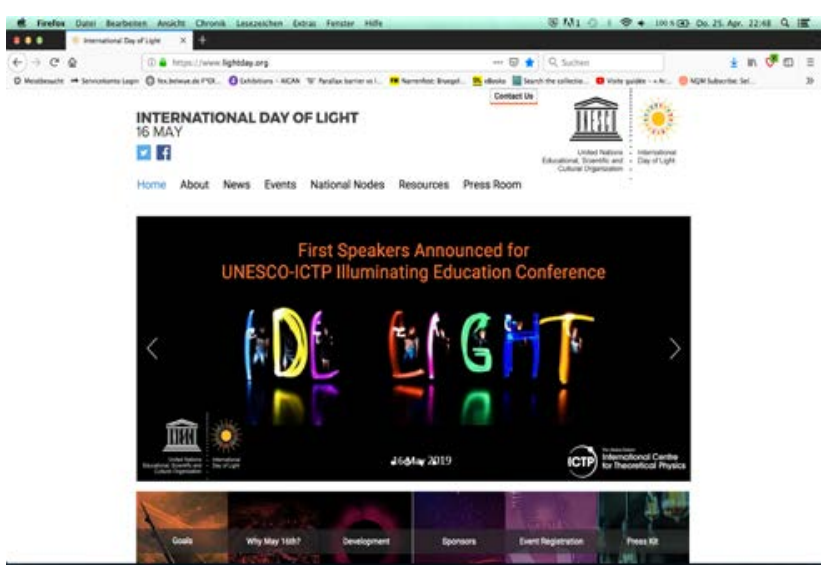

Fig. 17: - The landing page of the IDL

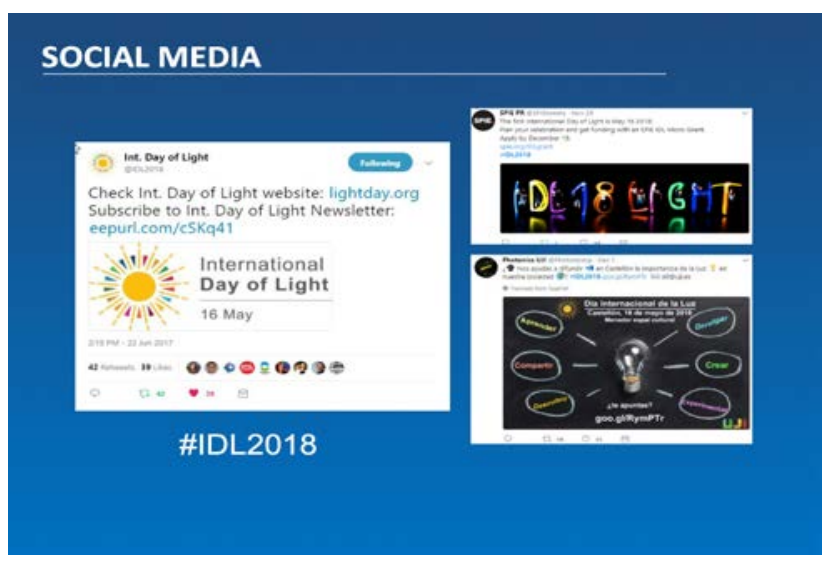

Fig. 19: - SPIE Social Media

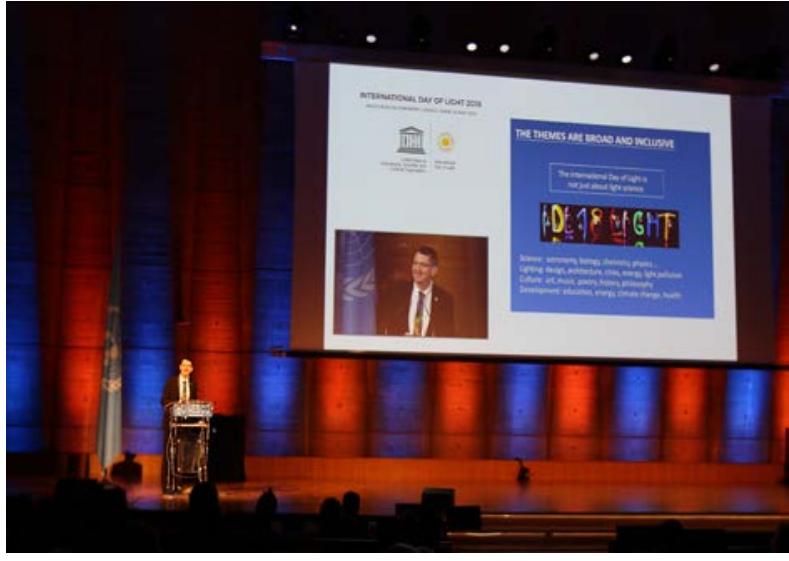

Fig. 18: - John Dudley at the IDL inauguration ceremony at UNESCO Paris 16.May 2018

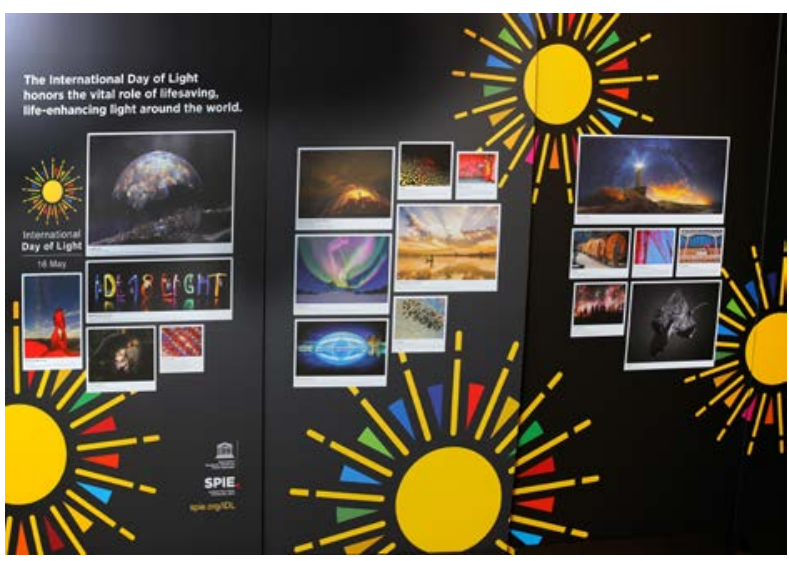

Fig. 20: - SPIE Poster collection at HQ UNESCO Paris 


\section{CONCLUSIONS AND PERSPECTIVES}

We can conclude, the International Day of Light is a motivational factor for our students to participate and to be involved in interdisciplinary project with the main topic in optics and photonics. In the presented projects were art students involved but also students with focus on media, informatics and engineering have made their contribution. "Good projects appear when people are working in different areas." [8].

The impact factor of our projects was very high, both in the region but also worldwide. Furthermore, we were able to captivate the attention of people in all age categories, from kids to seniors.

\section{ACKNOWLEDGMENT}

The author would like to thank all who supported him in the activities described in this article, especially Professor John Dudley, Past President of the European Physical Society ("Mister IYL" and "Mister IDL") and Dr. Eugene Arthurs Former SPIE CEO. Many thanks also to all the students at Offenburg University who helped implement these projects.

\section{REFERENCE}

[1] ***, "International Year of Light 2016," http://www.light2015.org/Home.html (30 April 2019)

[2] ***, "The International Year of Light and Light-based Technologies 2015 A Successful Community Partnership for Global Outreach,” Final Report, http://www.light2015.org/Home/About/IYL-Final-Report.html, SPIE Bellingham, Washington (2016)

[3] ***, "International Day of Light," https://www.lightday.org/ ( 30 April 2019)

[4] Curticapean, D., Vauderwange, O; Art and Photonics; SPIE Conference 11143, 15th Conference on Education and Training in Optics and Photonics, ETOP (2019)

[5] ***, "Ruby Laser," https://en.wikipedia.org/wiki/Ruby_laser ( 30 April 2019)

[6] ***, "Theodore Maiman," https://de.wikipedia.org/wiki/Theodore_Maiman ( 30 April 2019)

[7] ***, "HeNe Laser," https://de.wikipedia.org/wiki/Helium-Neon-Laser ( 30 April 2019)

[8] Daukantas, P., "2015: The IYL”, Optics \& Photonics News 01/2015; p. 28-35; OSA Washington/USA (2015) 